\title{
Metáforas para pensar la ciudad
}

\section{Enver Joel Torregroza-Lara ${ }^{1}$}

Recibido: 2016-06-21

Enviado a pares: 2016-06-23
Aprobado por pares: 2016-07-05

Aceptado: 2016-07-05

DOI: 10.5294/pacla.2018.21.1.3

Para citar este artículo / to reference this article / para citar este artigo

Torregroza-Lara, E. J. (2018). Metáforas para pensar la ciudad. Palabra Clave, 21(1), 36-

57. DOI: $10.5294 /$ pacla.2018.21.1.3

\section{Resumen}

El propósito del artículo es examinar el alcance de las metáforas para pensar la esencia de la ciudad contemporánea, a la luz de las propuestas filosóficas de Hans Blumenberg, Jean-Luc Nancy y Georg Simmel. El punto de partida de la reflexión es reconocer que la ciudad contemporánea difícilmente puede ser pensada como un fenómeno más del mundo, un objeto entre otros, pues hace tiempo que se ha convertido en el "mundo de la vida”, en el que la mayoría de los seres humanos desarrollan prácticamente la totalidad de su existencia. Al no estar disponible como una realidad objetivable teóricamente, el mundo de la vida de la gran ciudad difícilmente se deja atrapar en su esencia en la univocidad del concepto. Sin embargo, en el artículo se defiende la idea de que allí donde los conceptos no alcanzan, las metáforas pueden permitirnos establecer conexiones con lo que de otro modo permanecería oscuro.

\section{Palabras clave}

Ciudad; metáfora; Hans Blumenberg; Jean-Luc Nancy; Georg Simmel (Fuente: Tesauro de la Unesco).

1 orcid.org/0000-0001-5226-7637. Universidad del Rosario, Colombia. enverj.torregroza@urosario.edu.co 


\section{Metaphors for the City}

\section{Abstract}

The purpose of this paper is to examine the scope of the metaphors to reflect on the essence of the contemporary city, in light of the philosophical proposals of Hans Blumenberg, Jean-Luc Nancy and Georg Simmel. The starting point of this reflection is recognizing that the contemporary city can hardly be thought of as just one more phenomenon of the world, one object among others, as it has long since become the "world of life," where most human beings develop virtually all of their existence. By not being available as a theoretically objectifiable reality, the essence of the world of big city life can hardly be trapped in the univocal nature of the concept. However, the article defends the idea that, when concepts are not enough, metaphors help us to establish connections with what would otherwise remain obscure.

\section{Keywords}

City; metaphor; Hans Blumenberg; Jean-Luc Nancy; Georg Simmel (Source: Unesco Thesaurus). 


\section{Metáforas para pensar a cidade}

\section{Resumo}

O propósito do artigo é examinar o alcance das metáforas para pensar a essência da cidade contemporânea, à luz das propostas filosóficas de Hans Blumenberg, Jean-Luc Nancy e Georg Simmel. O ponto de partida da reflexão é reconhecer que a cidade contemporânea dificilmente pode ser pensada como um fenômeno mais do mundo, um objeto entre outros, pois faz tempo que se transformou no "mundo da vida", no que a maioria dos seres humanos desenvolvem praticamente a totalidade de sua existência. Ao fato de não estar disponível como uma realidade objetivável teoricamente, o mundo da vida da grande cidade dificilmente se deixa capturar em sua essência na univocidade do conceito. Contudo, no artigo defende-se a ideia de que ali onde os conceitos não alcançam, as metáforas podem permitirnos estabelecer conexões com o que de outro modo permaneceria escuro.

\section{Palavras-chave}

Cidade; metáfora; Hans Blumenberg; Jean-Luc Nancy; Georg Simmel (Fonte: Tesauro da Unesco). 


\section{Dificultades con el concepto tradicional de ciudad}

La realidad urbana contemporánea no puede explicarse satisfactoriamente a partir del concepto tradicional de ciudad. Esto es así porque la noción tradicional de ciudad remite a una realidad que se ha desdibujado y que se parece muy poco a lo que vivimos hoy en día en las grandes ciudades (Nancy, 2013, pp. 9-14). El contraste entre las formas de entender y vivir la ciudades en siglos pasados y la experiencia urbana contemporánea es notorio y ha sido tema de reflexión desde hace más de un siglo. No solo se ha teorizado sobre la manera como las primeras formas urbanas de la economía rural se transformaron en las ciudades modernas en las que se ha desarrollado la burguesía (Marx, 1983, pp. 390-391; Weber, 2000, p. 11; Pirenne, 1972, p. 140), sino que también se ha señalado cómo las limitaciones sociales de las comunidades cerradas de las pequeñas ciudades tradicionales estallan con la aglomeración tumultuosa de personas y cosas en la urbe de la sociedad de masas (Simmel, 2002, pp. 388-402) y la sociedad posindustrial (Nancy, 2013, p. 25). Se trata de un contraste que puede ser descrito como un paso entre dos categorías opuesta y en tensión: de la "cultura" a la "civilización", de la "comunidad" a la "sociedad”, del círculo social cerrado y centrípeto a la red social abierta y centrífuga (Nancy, 2013, pp. 12-13). Si bien algunas pequeñas ciudades contemporáneas o algunas zonas reducidas de las grandes ciudades de hoy aún pueden ser comprendidas a la luz del concepto tradicional de una comunidad localizada que recibe su sentido de una fuente externa, trascendente o sobrehumana, lo cierto es que en términos generales la dinámica de desarraigo y deslocalización de las grandes ciudades contemporáneas termina poco a poco imponiéndose en todas partes en un proceso lo suficientemente fuerte como para contener $y$ hasta provocar y proteger en su interior tales nostalgias de "ciudad" entendida como aldea acogedora.

Desde una perspectiva tradicional, una ciudad se puede definir a partir de su función: plaza, mercado, fuerte, puerto o templo. Incluso se la ha definido como continuación del hogar, extensión de la casa como espacio humano de protección y seguridad existencial (Bollnow, 1969, p. 135). La función le otorga a la ciudad su forma y su figura, su ser y su aspecto general, que 
es fácilmente representable en un retrato o mediante un símbolo. El "plano caballero" de las ciudades, esos retratos de la vista general de la ciudad que asumían el punto de vista de un viajero que se aproxima a lo lejos (Nancy, 2013, pp. 63-65), o los escudos de armas, por ejemplo, son recursos tradicionales de representación o simbolización de esa ciudad tradicional, vehículos que contemporánemente encuentran sus sucesores en las tarjetas de postal con imágenes de monumentos, las siluetas recortadas impresas en camisetas y los pocillos o los stickers con el nombre de la ciudad y alguna frase alusiva al estilo "I love New York".

La noción tradicional de ciudad es un concepto que no solo se aplica a la ciudad arcaica, la ciudadela o fortaleza como bastión militar, sede real o imperial, o a la ciudad santa que se despliega centrípetamente en función de un lugar sagrado o de un templo. La idea de una ciudad contenida en su propia figura, claramente localizada y definida a partir de su función esencial, está implícita también en la idea de polis, de aquel régimen común de vida reflejado en una constitución y que se puede intentar traducir por "ciudad-estado", "patria" o "cultura”, sin que ninguno de esos conceptos agote el significado que tenía para los antiguos griegos (Strauss, 2006, pp. 50-58).

Por supuesto, desde un comienzo, la ciudad antigua, la "polis", contuvo en su seno la condición de su extrapolación, al ser también nudo de caminos, mercado y lugar de inercambio con vocación de desplazamiento. Pero la ciudad pronto abandonó por ello la estabilidad de su fundación mítica y comenzó a desplegarse en la forma de un proceso lógico expansivo que no se ha detenido en el mundo moderno.

Jean-Luc Nancy (2013) ha descrito suficientemente el modo de ser de la ciudad contemporánea. Si bien su paradigma es la ciudad americana de Los Ángeles, la fenomenología de la ciudad contemporánea que propone no deja de apuntar a la tendencia característica de la realidad urbana a nivel global: el paso de una realidad en constante movimiento al de un movimiento constante de la realidad en cuanto tal. La realidad urbana contemporánea vive para desbocarse fuera de sí, en una lógica entrópica sin finalidad. 
La ciudad contemporánea ya no empata por ello ni con la idea de la ciudadela constituida en torno a una función que le da su ser y fugura ni en torno a la idea de una comunidad o de una cultura como inmanencia autorreflexiva, que se otorga a sí misma sus condiciones de posibilidad y recibe su sentido de fuentes sobrehumanas. Esto es así en parte porque el fenómeno global de la expansión urbana hace varias décadas que desborda los límites de los centros urbanos tradicionales y genera una realidad inimaginable hace siglos, que hace estallar la noción e imagen tradicional de ciudad (Nancy, 2013, p. 65). La ciudad contemporánea se deslocaliza constantemente, "se aleja", dice Nancy, y ya difícilmente se puede soñar con su realización como unidad plena (2013, p. 12). Semejante fenómeno ha obligado al uso de neologismos para intentar describirlo: megalópolis, conurbaciones, "posmetrópolis” (Soja, 2008), telépolis (Echeverría, 1994), etc., que son un síntoma claro de que no se sabe ya qué es una ciudad (Nancy, 2013, p. 12). Esto nos invita a pensar que lo mejor sería dejar de hablar de "ciudad” (p. 39), hablar de una "post-city age" (Webber, 1968) o anunciar el divorcio definitivo entre civitas y urbs y la consiguiente muerte de la ciudad (Choay, 2009).

Sin embargo, que el clásico concepto de ciudad sea inadecuado para describir la realidad urbana del siglo XXI se debe también al carácter inapresable de esta última, pues no se deja cobijar completamente por las categorías de ninguna disciplina científica específica y escapa, por ello, a la función estabilizadora y tranquilizadora del concepto. La ciudad ha dejado de ser un fenómeno más del mundo, un objeto entre otros, y ha pasado a ser el mundo mismo en el que los seres humanos desarrollan prácticamente la totalidad de su existencia. No basta con renunciar a la noción clásica de sustancia y adoptar conceptos metafísicos modernos subsidiarios, comolos de forma o función, pues en la ciudad contemporánea no hay precisamente formas estables y no se puede identificar una función definitoria. Hace rato que la ciudad dejó de ser lugar de cobijo para las expectativas humanas de realización de su ser más íntimo, el concepto aristotélico de ciudad como realidad orientada a la consecusión de la felicidad (Strauss, 2006, pp. 5058). La "ciudad" ya no es más una polis entendida como unidad orgánica al abrigo de la cual y por la cual podemos realizar nuestro destino. 
La ciudad de hoy permanece en obra (Nancy, 2013, pp. 80-83), no se somete a ninguna teleología y opera con una lógica propia, sin finalidad (pp. 40 y 43): la lógica del capital, que a partir de cierto punto no para de crecer desde sí mismo (Simmel, 2002, p. 398), y la lógica de la técnica, del "agenciamiento de medios sin fin", en la que fines y medios se confunden (Nancy, 2013, p. 43). La ciudad tiene cada vez más el aspecto de un tipo de realidad que escapa al control humano, una fuerza que domina la vida humana y que pareciera absoluta. Al haber adquirido vida propia, hemos arribado al momento histórico en el que no es gracias a la ciudad, sino frente a ella, como nos hemos de comprender los seres humanos.

La ciudad contemporánea parece algo que podemos producir, pero que por poco no somos capaces de representar. Habría que poner "ciudad" entre comillas, pues no parece válido seguir denominando su realidad con ese lenguaje arcaico, ni recurrir al artículo determinado en singular. Tampoco es tema exclusivo de ninguna disciplina científica específica (LeGates, 2011, pp. 8-11). No posee la identidad de una realidad específica escindible de otras. Elude con facilidad los empeños por conventirla en "objeto" de investigación y está lejos de ser un tema domeñable por un aparato metodológico que controle sus variadas ocurrencias.

Cada aproximación científica logra por supuesto extraer un aspecto esencial de una realidad que no se entrega completamente por principio a él. Pero así despliegue la precisión característica de su enfoque, la lectura de cada disciplina apenas alcanza a generar el ajuste habitual a una realidad previamente abierta por sus propios conceptos fundamentales, cuyo campo de aplicación, sin embargo, no se corresponden nunca plenamente con el espacio al que remite la noción cotidiana de "ciudad" o de "urbe", mucho más empírica y pragmática (LeGates, 2011, pp. 8-11), pero con un referente mucho más abigarrado y complejo. Se puede por ello estudiar cualquier cosa de la ciudad o de lo que en ella ocurre, pero no la "ciudad" como tal. La esperanza de acercarse a la ciudad contemporánea con neologismos no hace sino reproducir con otros nombres el vacío de identidad de una realidad que no es dominable completamente por la estética, o la arquitectura, el urbanismo, la economía, la biología, la sociología, la historia, la filosofía o la literatura. 


\section{La ciudad: "mundo de la vida" y caverna}

No es pues porque "la ciudad" o "lo urbano" sean conceptos de frontera o conceptos fundamentales de unas disciplinas que estos deben convertirse en objeto de reflexión filosófica. Es su propia condición problemática la que obliga a la filosofía a trabajar en estos temas (Correa, 2000). Cuando hablamos de ciudades y realidades urbanas, resulta significativo que los desarrollos teóricos que tratan de sentar las bases de su entendimiento científico contemporáneo tengan la mayor parte de las veces un contenido, una expectativa, si no un modo de proceder que cabe calificar como filosófico (Hiernaux, 2006, p. 9).

La procupación por entender la realidad urbana contemporánea, que oscila entre el urbanismo, la economía, la arquitectura, la geografía humana, la sociología y los estudios culturales, no puede evitar reconocer que la naturaleza misma del asunto radica en su inapresabilidad teórica, y todas esas disciplinas están muy lejos de admitir que hay algo así como unos límites definidos y ubicuos para un concepto de lo urbano y de la ciudad (LeGates, 2011, pp. 8-11). Tampoco basta con depositar las esperanzas de superar los vacíos de cada punto de vista disciplinar con una ingenua sumatoria de perspectivas multidisciplinares, pues no son aspectos complementarios de lo mismo, sino lecturas de realidades definidas de un modo tal que su sustancia última es incompatible entre sí.

No se trata de discutir aquí si hay que seguir cumpliendo o no con la tarea de ofrecer un conocimiento confiable de la realidad urbana, fundado en observaciones reguladas y conceptos funcionales que permitan desarrollar una "ciencia de la ciudad", una urbanología. Después de todo, sigue siendo posible y necesaria la ciencia de todo lo que ocurre en la ciudad. Pero la empresa de gobernar la totalidad de la realidad urbana con un aparato conceptual unívoco se evidencia lo suficientemente disfuncional como para que no sea por principio oportunamente rechazada, más allá de qué tan cuestionables sean las motivaciones políticas, sociales, psicológicas o existenciales de un empeño de esta clase.

La filosofía puede, sin embargo, encarar la tarea de pensar lo que escapa al concepto. Si se comprende la realidad urbana contemporánea 
como un caso de inconceptuabilidad (Unbegrifflichkeit, el concepto es de Blumenberg, 1995 y 2007), puede entonces comprenderse mejor el lugar de la filosofía en la reflexión sobre lo urbano. La inconceptuabilidad corresponde no solo de manera negativa con aquellas zonas de la realidad que aún escapan a la elaboración conceptual de las ciencias o las teorías. Más bien hace referencia de manera positiva a aquellas "realidades en que vivimos" del "mundo de la vida" (Lebenswelt); unas realidades que solo pueden ser expuestas con recursos retóricos indirectos (metáforas, anécdotas, mitos y símbolos), pues para esos casos los conceptos no son suficientes o se han agotado (Blumenberg, 1995, pp. 97-98 y 100; Durán, 2010, pp. 120 y ss.).

Puesto que toda experiencia sensible está cargada de significaciones y valoraciones, para Husserl el mundo de la vida es la "infraestructura de sentido" que hace de la experiencia humana algo mucho más rico que lo que se presenta de manera efectiva (Herrera, 2010, pp. 256-257). El mundo de la vida siempre está dado de antemano como el espacio significativo en el que somos humanos. Toda experiencia se da sobre su suelo y en él "tienen significaciones no solo las palabras y los signos, sino las cosas mismas" (Blumenberg, 1995, p. 100). Allí habita una racionalidad que se trasluce en la soprendente significatividad de las metáforas, los mitos, las anécdotas, los símbolos y hasta las cosas mismas, motivo por el cual es posible entender por qué lo racional nunca se reduce a lo conceptual (Blumenberg, 2007, p. 9), pues esto último es apenas uno de los tantos instrumentos de la razón.

Una filosofía del "mundo de la vida” es de inspiración fenomenológica no solo por la deuda que tenemos con Husserl al haber propuesto semejante fórmula impregnada de significado. El mundo de la vida es la realidad que se suele dar por sentado y que, por obvia y fundante, es pasada de largo cada vez que intentamos ir a la caza de algún objetivo, pues sirve de soporte a todo movimiento. Funciona como el piso sobre el que andamos, que puede convertirse rápidamente en obstáculo o lugar de tropiezo si nos ponemos a pensar en él y no solo a usarlo. Al "mundo de la vida" Blumenberg (2011, p. 497) lo llama "suelo de la vida", con lo que al mismo tiempo corrige a Husserl con otra poderosa metáfora. 
En cuanto "lugar común" tanto en el sentido literal como en el extendido de esta expresión el suelo de la vida en el que nos movemos cotidianamente pareciera escaparse al pensamiento justamente por ser lo más cercano a la experiencia. Como el mundo de la vida, cualquier esfuerzo por abordar teóricamente la realidad de la ciudad no hace sino transitar tangencialmente por sus aristas. Resulta difícil pensar directamente con conceptos aquello que parece ser la condición de posibilidad del pensamiento conceptual. No parece fácil doblegar como objeto, "tematizar" diría Husserl, aquello que hace posible la actitud objetiva. En el caso de "la ciudad", esto se muestra como la dificultad de intentar cargar o transportar en una abstracción lo que en sí mismo es el soporte de toda abstracción. La ciudad no solo es el suelo sobre el cual nos movemos cotidianamente y pensamos, no solo es nuestro mundo de la vida, sino que también es el lugar en el que la abstracción tiene su génesis; abstracción que incluye, por supuesto, a la filosofía misma, como manifestación cultural que solo tiene lugar en la ciudad (Durán, 2015, pp. 163-164).

Tanto George Simmel como Hans Blumenberg, ambos fuertemente influenciados por Husserl, han señalado cómo la ciudad es justamente el lugar que hace posible toda abstracción. En su clásico ensayo de 1903 "Las grandes ciudades y la vida del espíritu” (Die Grossstädte und das Geistesleben), Simmel describe las "grandes ciudades", las “metrópolis", como lugares por excelencia de la economía monetaria, cuyo proceso de desarrollo va aparejado al del entedimiento lógico, con el que posee un vínculo íntimo. El motivo de este vínculo estrecho radica en que tanto el dinero como el cálculo permiten "la pura objetividad en el trato con los hombres y las cosas” (Simmel, 2002, pp. 390-391). En las grandes ciudades modernas - que es como Simmel denomina a la realidad urbana que nace a fines del siglo XIX y se prolonga hasta hoy-, la capacidad para generar distancia entre productor y consumidor en el proceso de intercambio se potencia hasta un punto en que la producción y el intercambio quedan reducidos a la abstracción máxima del cálculo, como meros flujos de símbolos y conceptos.

Blumenberg comenta brevemente este famoso texto de Simmel en un capítulo de su libro Salidas de caverna (Höhlenausgänge) titulado "La 
ciudad como caverna" (1989, pp. 76-81). Sintetizando el ensayo de Simmel, Blumenberg afirma que la ciudad es el espacio que favorece el mayor grado de abstracción en la captación de la realidad, al reemplazar por conceptos aquello que no está propiamente presente pero sí está disponible, con el fin de administrar la realidad exterior de la cual la ciudad depende (p. 77). Tanto el desarrollo de la economía monetaria en la ciudad como el predominio que se da en ella de la inteligencia son solo las dos caras de lo que Blumenberg llama "el distanciamiento de la realidad". Para Blumenberg, el distanciamiento de la realidad no es otra cosa que el proceso necesario que desarrolla el ser humano para construirse un espacio de significatividad (2003b, pp. 24 y 125-127); un espacio que se puede denominar "mundo" o "cultura" (Torregroza, 2014, pp. 317-332), y que en esencia está constituido por elaboraciones "simbólicas", en el sentido amplio que Cassirer le dio a la noción de "símbolo" en su antropología filosófica (Blumenberg, 1999, p. 125).

En ese marco de comprensión antropológica, la ciudad es el espacio privilegiado de la artificialidad y la distancia, pues le quita realidad a todo aquello que no sea su producto o atraiga en su seno como materia prima. Constituye así un "espacio mítico de protección" de todo lo que no puede ser representado, simbolizado o conceptualizado: le quita realidad a lo que no es ciudad y está afuera, así la ciudad dependa de ello. Blumenberg condensa la explicación con una "metáfora absoluta" o "de fondo" : "la ciudad es la repetición de la caverna por otros medios" (1989, p. 76). Del mismo modo que la caverna platónica, la ciudad permite tomar distancia de la realidad mediante su olvido y la suplanta con una realidad derivada y parasitaria.

El crecimiento de la ciudad resulta directamente proporcional al de las relaciones abstractas (Blumenberg, 1989, p. 77). Al ser enteramente una

2 Por metáfora absoluta entiende Blumenberg aquella que no puede ser reducida o traducida en un concepto, pues no se deja "reconducir a lo propio, a la logicidad" (2003a, pp. 44-45). Las metáforas absolutas o "fundamentales" (2001, p. 140) constituyen fórmulas retóricas que no son de uso casual, sino estrictamente necesarias cuando los conceptos no alcanzan. Configuran entramados de metáforas asociadas o "metafóricas", que sirven de horizonte de sentido y de trasfondo para el despliegue con sentido de conceptos particulares. Están "detrás” o "debajo" de los conceptos y no son simples estadios previos a su consolidación, sino su fuente de significatividad (Torregroza, 2014, pp. 53-59). Ejemplos de metáforas absolutas son las siguientes: la caverna, el libro, la luz y la metafórica náutica asociada al naufragio (Durán, 2010). 
hechura del hombre, la ciudad despliega formas variadas de pérdida de la realidad: es el espacio de la economía como administración abstracta de lo ausente pero disponible, pero también es el lugar privilegiado de producción plástica figurativa como creación originaria de fuentes artificiales de sensibilidad ante la pérdida de sensibilidad natural generada por el imperio de la objetividad económica y científica que en la ciudad se despliega. La ciudad es, además, el olvido de la realidad externa mediante su interiorización y administración, pues allí la "naturaleza", lo no urbano, es objeto de planificación y gobierno: ya sea en la forma de maceta, zoológico, parque natural disponible para la caminata ecológica o reserva natural de recursos futuros, la totalidad de la naturaleza existe "en" y "para" la ciudad. Finalmente, la ciudad es el símbolo por antonomasia de la obtención veloz de éxito y fortuna, precisamente por su falta de realidad, al estar sobrecargada de estímulos (pp. 78-81).

La descripción de Blumenberg (2001, pp. 139-171) no es en principio una caracterización negativa de la ciudad, pues la caverna no es negativa o positiva en sí: si Platón vio en ella la ignorancia condenable, Cicerón logró resaltar también su lado favorecedor como lugar de abrigo. La caverna también es un símbolo de la autoafirmación humana y tiene un valor positivo antropológico en Blumenberg: la antropogénesis acontece en la caverna como espacio que hace posible el distanciamiento del absolutismo de la realidad, pues, al poner una cosa "en vez de otra", la caverna permite aliviar la carga de la realidad y lidiar con su habitual e instransigente prepotencia. La caverna hace presente interiormente lo exterior y por eso es también el símbolo del arte y del ensueño, pues en su seno es posible soñar "aquello que supera la conciencia”, sin tener que enfrentarlo directamente.

La ciudad, por supuesto, es diferente de las cuevas de Altamira, así la caverna sea su anticipo, pues la ciudad no permite el ensueño, la magia o la ilusión, sino que los expulsa: todo lo calcula, abstrae y objetiva en concepto. En este sentido, la ciudad es una suerte de caverna privada de su principal rendimiento antropológico: el poder descargar al abrigo de sus paredes, con la magia de los símbolos, la experiencia traumática de una realidad exterior prepotente sobrecargada de estímulos mostruosos. En 
este punto, Simmel complementa a Blumenberg, pues son las potencias individuales que se desarrollan en la ciudad como reacción a la nivelación objetiva las destinadas a generar el arte y el ensueño necesario para lidiar con lo que supera la conciencia, mediante la creación plástica, la literatura o la filosofía.

Como motor de toda abstracción, la ciudad parece escapar también a la red conceptual que continuamente produce con el fin de administrar y gobernar todo lo que la atraviesa. Su origen, la verdad de su ser como construcción parasitaria de una realidad que la supera, o como refugio transitorio para olvidarse de ella, está también sometido al ocultamiento y al olvido, y solo parece revelarse en una metáfora que es a su vez un mito: la caverna.

El hecho de que Blumenberg interprete la caracterización simmeliana de la ciudad a la luz de la metáfora de la caverna no es gratuito: el mito de la caverna es el de un tránsito, un paso de un estado a otro, y la metáfora funcional allí contenida es el movimiento de salida de la caverna (o el retorno a ella) y no la caverna propiamente dicha. Después de todo, Simmel invita a pensar la ciudad como una realidad en movimiento: la experiencia de la ciudad es un tránsito entre lo cerrado y lo abierto, entre un ser pobre de mundo y un configurar mundo, entre la nivelación objetivadora y la singularidad extravagante de las individualidades subjetivas; en suma, un ir y volver que Simmel caracteriza como paradójica tensión y donde no hay síntesis dialéctica posible.

Para comprender la realidad urbana moderna, Simmel (2002) se asoma a su dinámica interna mediante la identificación en los términos espaciales de cercanía y distancia el principio configurador de la libertad individual en una sociedad de masas: la cercanía en la que habitan los ciudadanos de las grandes ciudades es el acicate no solo del anonimato, la indiferencia e incluso la insociable sociabilidad de sus habitantes, sino también de la libertad individual, al abrir las posibilidades de configuración de una subjetividad cada vez más acentuada. Simmel también logra comprender esa dinámica de la realidad urbana de modo indirecto, gracias a la metáfora del capital. En su caso, no hay una filosofía de la ciudad sino indirectamente, como fi- 
losofía del dinero, ${ }^{3}$ pues este es el vehículo más adecuado para transportar el sentido de lo urbano: su valor simbólico indiferente, objetivo y trascendente sirve a la vez de condición de posibilidad (e imposibilidad, porque paradójicamente también la dificulta) para el despliegue de una subjetividad individual poderosa, deferente y creativa. En la filosofía de Simmel, el dinero es la metáfora fundamental de la vida (Blumenberg, 2001, pp. 177192; Simmel, 2013, pp. 35-36).

La gran ciudad es para Simmel el lugar de la aglomeración y, por ende, de la sobrecarga de estímulos nerviosos, lo cual provoca la inevitable reacción de una racionalidad cada vez más abstracta que anestesie los efectos de una abigarrada y desboradada realidad en movimiento. La gran ciudad despliega según Simmel una particular violencia: al mismo tiempo que impone una situación en exceso exigente para nuestras disposiciones nerviosas, al acumular personas y cosas frente a las cuales no nos queda más remedio que desarrollar una indolencia fisiológica, ser indiferentes o habituarnos a rechazar con pragmática antipatía, la ciudad también crea escudos que protegen la vida subjetiva, como la racionalidad lógica, la pura objetividad del concepto y la indiferencia frente a lo cualitativo propia del cálculo monetario y el dinero, escudos que terminan al final por amenzar, paradójicamente, las particularidades y riquezas de esa vida subjetiva e individual que pretendían proteger. Todo se sintetiza en la inevitable metáfora líquida del dinero: en las grandes ciudades "todas las cosas nadan con el mismo peso específico en la contantemente móvil corriente del dinero" (Simmel, 2002, p. 393).

En contraste con las pequeñas ciudades, en las que la esfera vital está en lo esencial "concluida en y consigo misma", dice Simmel, la vida interior de la gran ciudad se extiende como "crestas de olas" sobre un ámbito que lo supera: no solo por sus efectos nacionales o internacionales, sino por su "virtualidad", el hecho de que su tamaño funcional va mucho más allá de sus fronteras físicas, existiendo la ciudad "más allá de la globalidad de sus efectos" (p. 400). Simmel observa ya en 1903 que las grandes ciudades

3 El mismo Simmel en una nota a pie al final de su ensayo sobre las grandes ciudades (2002, p. 402) reconoce que todo lo allí contenido está desarrollado de manera más amplia en su Filosofía del dinero. 
desbordan nuestra capacidad de asimilación y representación y nos ofrecen una realidad que ya no es cobijo alguno, sino de la que, antes bien, debemos protegernos. La ciudad moderna parece desde entonces estar muy lejos de su origen cavernario, en la hipótesis metaforológica de Blumenberg, y exige, más bien, la proliferación de nuevas cavernas que nos protejan de su absolutismo.

\section{Metaforicidad de la ciudad}

Todo lo que hay, si de ser realistas se trata, es una serie no gobernable de relatos de ciudades o, en sentido más amplio e incluyente, de descripciones de ciudades que, vehiculadas en diversos soportes y medios (visuales, auditivos, escritos), nos hablan de ciertas experiencias de tránsito por ciudades específicas, que no permiten por ellas mismas definir un punto de vista privilegiado o una experiencia dominante. Por supuesto, el ego del espectador siempre tiende a presentarse como punto de vista privilegiado, pero nadie tiene por qué asumir que París es el París de Benjamin, que Roma es la Roma de Simmel o que Los Ángeles son Los Ángeles de Jean-Luc Nancy, por poner solo ejemplos filosóficos y no solo los numerosos e inagotables ejemplos de la narrativa (la Dublín de Joyce, etc.), la poesía (la Nueva York de García Lorca, la Buenos Aires de Borges, etc.), etc.

Por supuesto, alguien puede afirmar que las variadas experiencias de ciudad están condicionadas por lo que las ciudades son cultural, histórica, económica o socialmente. Pero semejante creencia supone que es posible investigar lo que las ciudades son en sí mismas, de modo independiente de tales representaciones particulares. Este supuesto pretende trazar asíla frontera entre una visión teórico-objetiva de la realidad y sus representaciones "subjetivas", siendo que es una frontera meramente imaginada, pues está construida al interior de un conjunto de representaciones fenoménicas que contienen tanta dosis de contenido de realidad como de elaboración simbólica de esta. La única diferencia efectiva que se traza de ese modo es entre el postulado racional de una realidad como depósito inagotable de sus representaciones y cada una de las respresentaciones efectivas como realización de alguna de todas esas posibilidades. 
Las diferentes elaboraciones de la experiencia urbana ayudan a construir el entramado de recursos simbólicos a partir de los cuales es pensada, imaginada y descrita cada ciudad. Sirven, por decirlo en estilo kantiano, de elementos constitutivos de las formas impuras de la sensibilidad urbana: son condiciones de posibilidad impuras a priori de la experiencia de cada ciudad. Tales elaboraciones teóricas, literarias, filosóficas o plásticas, independiente de su alcance o del tamaño de su impacto en la cultura, lejos de limitarse a reproducir una particular experiencia personal, terminan por servir de soporte simbólico a futuras vivencias de la ciudad y proveen de un lenguaje para vehicular lo que en ellas se experimenta u ofrecen una captación intuitiva que sirve de representación icónica o símbolo —en el sentido más convencional — de su realidad. Por ello, ante estas elaboraciones, no se sabe dónde comienza lo objetivo ni lo subjetivo de la ciudad. También son productos de la ciudad para pensarse a sí misma, así no aboguen necesariamente por un trato objetivo (esto es, "indiferente", en el sentido de Simmel) con ella, y así en todas esas representaciones de lo urbano habite el distanciamiento de la realidad inherente a toda elaboración simbólica.

La experiencia de ciudad que se refleja en cada relato o descripción literaria o plástica es singular y fragmentaria y está lejos de ser sistematizable o de servir de "caso" para un generalización fenoménica, como bien muestra Walter Benjamin con su filosofía de la ciudad (Supelano-Gross, 2014, p. 151). La experiencia de ciudad invita a desplazar las fronteras entre las categorías modernas básicas con las cuales comprendemos nuestro mundo, y la distinción entre lo objetivo y lo subjetivo no es la única invención moderna que sacuden y desajustan. Del mismo modo, la literatura, y la filosofía que da forma a esas experiencias, nos conduce a transitar de un espacio de sentido a otro, mediante el transporte de significados útiles para describir realidades conocidas a escenarios donde se asoma lo impensado. La literatura sobre la ciudad, que a la vez que reconoce su ilegibilidad intenta, no obstante, describirla (Gómez-Montero, 2014), y la filosofía, en su esfuerzo por pensarla reconociendo que no la puede reducir al concepto, son ambas suelo propicio para la metáfora y otros rodeos retóricos como vehículos de representación de lo que la ciudad provoca. Se trata del modo filosófico de proceder estándar y no de ninguna novedad metodológica, así 
lo parezca. Por ejemplo, Walter Benjamin, uno de los paradigmas de toda filosofía de ciudad, no piensa ni recorre la modernidad o la ciudad moderna en cuanto tal. Piensa y recorre ciudades concretas, como París, Berlín, Nápoles o Moscú, que en su pensamiento devienen símbolo de algunos problemas de la modernidad, debidamente localizados (Kohan, 2007, pp. 14-15).

La necesidad contemporánea de recorrer la ciudad con metáforas no surge entonces de una mera dificultad metodológica típica de todo empeño teórico por dar cuenta de una realidad inasible. La ciudad impone la metáfora, o para decirlo más técnicamente, impone la "metaforicidad". La ciudad es transporte, meta-phora, modula "todas las variaciones del trans: transporte, transformación, tránsito, transfixión, transinmanencia desquiciada" (Nancy, 2013, p.14). Lugar no solo de construcción sino de deconstrucción, termina por deconstruir la idea misma de "lugar", rompe con la idea de "territorio", es la patria del "desarraigo" (p. 107), "hija y madre del desplazamiento" (p. 109).

Por una parte, la ciudad se disemina. La ciudad, como afirma Nancy en su descripción fenomenológica, "es primeramente una circulación, es un transporte, un recorrido, una movilidad, una oscilación, una vibración”, puesto que "de todas partes remite a todas partes y al afuera de sí misma" (p. 38). Como mundo de la vida pletórico de cosas que significan, la ciudad vive en constante remisión significativa. "Cada lugar urbano remite a otros y solo existe o solo consiste en esa remisión” (p. 41). No en vano la ciudad comercia, "en la más amplia acepción de la palabra" (p. 39), sin descanso: "abierta por todas partes, atareada con el intercambio y la circulación, el tráfico, la traducción, la mediación y la especulación” (p. 40). En la ciudad, el sentido circula sin término, se desplaza sin parar, nunca siendo siempre la misma sino volcada a ser otra cosa fuera de sí. Como la caverna, cabe añadir, que siempre nos lanza fuera de ella misma.

Por otra parte, la ciudad se descarga y es descarga: lugar del consumo, se consume a sí misma y se dilata desorbitadamente. Provoca una luz que cada noche ilumina el cielo al mismo tiempo que escreta suciedad sin compasión. Es Babilonia, mito que conjuga la oscilación urbana entre el supra- 
mundo y el inframundo, entre la luminosidad de la elevación sagrada de sus creaciones y productos y la sórdida oscuridad de sus bajos fondos (pp. 6871). Si la ciudad tiene alguna estructura, es la de un inconsciente (p. 48). Es más sujeto que objeto. Elaboración simbólica interior de una realidad externa que la supera: de nuevo, la caverna.

"Metáfora" deviene entonces otra metáfora adecuada para pensar la esencia de la ciudad. La ciudad no solo se piensa y describe metafóricamente, sino que es ella misma metáfora, un transporte de sentido, y su modo de ser es el de la metaforicidad misma: el salir y entrar de la caverna.

Pensar la ciudad metafóricamente es el proceder propio de una filosofía del "en vez de" que no renuncia a pensar por el hecho de no poseer la cosa misma, pero que sabe que la cosa misma también es ella un desplazamiento, un movimiento que no se deja apresar si no navegamos al mismo tiempo con él. En este sentido, asumir la metáfora como metáfora a su vez de todo tránsito, de todo comercio, de todo transporte y traducción resulta ser un recurso dúctil para cruzar esas aguas fluidas de la realidad en movimiento que es la realidad urbana de hoy.

\section{Conclusión}

Diciéndolo en lenguaje blumenberguiano, la ciudad contemporánea escapa a nuestras capacidades conceptuales de representación. Acontece con ella lo mismo que con el mundo, o el ser: totalidades que no se pueden tener a la vista, que son ajenas a la intuición que da contenido al concepto - para decirlo kantianamente —, pero que tampoco se pueden tener "a la mano" - para decirlo heidegerianamente-, como útiles disponibles en nuestro mundo circundante cotidiano.

Nancy identifica en el modo de ser de la realidad urbana contemporánea algo que ya Simmel había visto: la megalópolis es el lugar de la sociedad, de la civilización, no de la comunidad ni de la cultura localizada. Puede que aparentemente contenga "territorios", pero todos ellos permanecen en continuo trance de trasformación, se dan transitoriamente o están en el tránsito de ser otra cosa. No hay arraigo en la ciudad contemporánea 
y su suelo es móvil. Algo que resulta difícil de asimilar si aceptamos que la ciudad se ha convertido en nuestro "suelo de la vida".

La vida en las ciudades contemporáneas parece por tanto flotar en un suelo móvil. Permanece en la inestablidad oscilatoria del entrar y salir de la caverna. Pues si bien la ciudad, en cuanto continuación de la caverna, es el lugar de toda abstracción y simbolización, el espacio del "en vez de" que define toda retórica, hace rato que dejó de ser un abrigo que nos cobija de la prepotencia de la realidad, y deviene más bien una realidad prepotente de la que queremos tomar distancia o frente a la cual nos hacemos humanos. La ciudad, que en principio es el acicate de la individualidad y la singularidad anímica frente al imperio ominoso de la rigidez social aldeana y rural, en la sociedad de masas continuamente está amenazada por el peligroso pozo sin fondo de las pretensiones de objetividad, el cálculo y el dinero, que todo lo tasan con la misma medida y ahogan por la vía de la nivelación la irremplazabilidad y las particularidades de los sujetos (Simmel, 2002). La vida en las grandes ciudades oscila, como dice Simmel, en una permanente lucha por flotar y destacarse en unas corrientes que nos superan, al mismo tiempo que nos entregamos cómodamente a esas "corrientes" en las que apenas necesitamos "movimientos natatorios propios" (p. 401). El suelo de la vida es hoy más un océano que una orilla, más un mar en el que la existencia humana navega que un puerto seguro al cobijo de la tierra firme (Torregroza, 2014).

La ciudad de hoy tiene el modo de ser inapresable de la metáfora, un "indecidible" que no se deja atrapar en una síntesis que supere las tensiones de las oposiciones que lo fundan y lo imposibilitan a la vez: ser lugar del no lugar, ser la permanencia del desplazamiento, el puerto al que no se arriba, sino que se navega. "Metáfora" puede ser, por tanto, la metáfora de la ciudad contemporánea, así la caverna siga siguiendo una poderosa metáfora de su génesis. La ciudad solo es una realidad que invita e incluso obliga a la metaforicidad para ser representada al escapar a las posibilidades de conceptualización; también es una realidad cuyo modo de ser real es el de la metaforicidad misma. 


\section{Referencias}

Blumenberg, H. (1989). Höhlenausgänge. Fráncfort: Suhrkamp.

Blumenberg, H. (1995). Naufragio con espectador. Madrid: Visor.

Blumenberg, H. (1999). Las realidades en que vivimos. Barcelona: Paidós.

Blumenberg, H. (2001). Ästhetische und metaphorologische Schriften. Fráncfort: Suhrkamp.

Blumenberg, H. (2003a). Paradigmas para una metaforología. Madrid: Trotta.

Blumenberg, H. (2003b). Trabajo sobre el mito. Barcelona: Paidós.

Blumenberg, H. (2007). Theorie der Unbegrifflichkeit. Fráncfort: Suhrkamp.

Blumenberg, H. (2011). Descripción del ser humano. Buenos Aires: FCE.

Bollnow, O. (1969). Hombre y espacio. Barcelona: Labor.

Choay, F. (2009). El reino de lo urbano y la muerte de la ciudad. Andamios, 6(12), 157-187.

Correa, B. (2000). La ciudad en la reflexión filosófica. En C. Torres, F. Viviescas y E. Pérez (eds.), La ciudad: hábitat de diversidad y complejidad (pp. 64-71). Bogotá: Universidad Nacional de Colombia.

Durán, L. (2010). Metáfora y mundo de la vida en Hans Blumenberg. Revista de Filosofía, 35(2), 105-127.

Durán, L. (2015). Elogio de la ciudad: semblanza de la filosofía como fenómeno urbano. Thémata: Revista de Filosofía, 51, 145-167.

Echeverría, J. (1994). Telépolis. Barcelona: Destino. 
Gómez-Montero, J. (2014). Polis o Megacity - Pesadilla y deseo. Modelos de (i)legibilidad literaria de la ciudad entre Europa y América. Les Ateliers du SAL, 4, 143-170.

Herrera, D. (2010). Husserl y mundo de la vida. Franciscanum, LII(153), 247-274.

Hiernaux, D. (2006). Repensar la ciudad: la dimensión ontológica de lo urbano. Liminar: Estudios Sociales y Humanísticos, 4(2), 7-17.

Kohan, M. (2007). Zona urbana: ensayo de lectura sobre Walter Benjamin. Madrid: Trotta.

LeGates, R. (2011). Prologue: How to study cities. En R. LeGates y F. Stout (eds.), The city reader (pp. 8-11). Londres: Routledge.

Marx, K. (1983). Grundrisse der Kritik der politischen Okonomie. Berlín: Dietz Verlag.

Nancy, J.-L. (2013). La ciudad a lo lejos. Buenos Aires: Manantial.

Pirenne, H. (1972). Las ciudades de la Edad Media. Madrid: Alianza.

Simmel, G. (2002). La metrópoli y la vida mental [Die Grossstädte und das Geistesleben]. En Sobre la individualidad y las formas sociales (pp. 388-403). Quilmes: Prometeo.

Simmel, G. (2013). Filosofía del dinero. Madrid: Capitán Swing.

Soja, E. (2008). Postmetrópolis: estudios críticos sobre las ciudades y las regiones. Madrid: Traficantes de Sueños.

Strauss, L. (2006). La ciudad y el hombre. Buenos Aires: Katz.

Supelano-Gross, C. (2014). ¡Cómo hacen frente las cosas a las miradas! Walter Benjamín y la mirada de lo urbano. Universitas Philosophica, 62, 147-168. 
Torregroza, E. (2014). La nave que somos: hacia una filosofía del sentido del hombre. Bogotá: Pontificia Universidad Javeriana.

Webber, M. (1968). The post-city age. Daedalus, 97(4), 1091-1110.

Weber, M. (2000). Die Stadt. Tubinga: Mohr (Paul Siebeck). 